\title{
Management of Foreign Bodies in the Mouth, Nose and Ears in Children in the Emergency Room
}

\author{
Florian Bast, ${ }^{1,}$ Corina Lee, ${ }^{2}$ Natalie von Jaschke, ${ }^{3}$ and Heidi Olze ${ }^{3}$ \\ ${ }^{1}$ Guy's and St. Thomas' Hospital, Department for ENT, Rhinology, Facial plastics, London, UK \\ ${ }^{2}$ Chelsea and Westminster Hospital, Department for Paediatric Anaesthesiology, London, United Kingdom \\ ${ }^{3}$ University Hospital Charite, Department of Oto-Rhino-Laryngology, Campus Virchow-Klinikum Berlin, Germany \\ 'Corresponding author: Florian Bast, Guy's and St. Thomas' Hospital, Department for ENT, Rhinology, Facial plastics, London, UK. Tel: +49-1784155269, E-mail: \\ florianbast@gmx.de
}

Received 2017 April 06; Accepted 2017 July 29.

\begin{abstract}
Background: In daily ENT practice foreign bodies in children are a frequent occurrence. In most instances, removal of the foreign body is easily accomplished. In some cases removal is only possible under brief general anesthesia.

Objectives: The present work is intended to provide an overview of the first aid management of foreign bodies in the ENT field.

Methods: The study was conducted at the Charite University Hospital Berlin, campus Virchow Klinikum (Germany). All children referred to the otolaryngologist on duty in the emergency room between 2009 - 2013 with a suspected foreign body were included in the retrospective study.

Results: 517 children were included in our study. We removed foreign bodies from the following sites: ear 161, nasal cavity 237, nasopharynx 8, and oropharynx 29. Furthermore, 15 foreign bodies were found at other sites in the aerodigestive tract. 51 foreign bodies were removed under general anesthesia.

Conclusions: The management of foreign bodies in ENT in children should be adapted to the location, the nature of the foreign body and the child's age in order to ensure a safe and gentle removal. Interdisciplinary collaboration is required in particular to avoid complications.
\end{abstract}

Keywords: Children, Foreign Body, Removal, Emergency Room

\section{Background}

In everyday ENT-medical practice, foreign bodies in children are a frequent occurrence. The primary objective of treatment is immediate and painless removal. This is facilitated by a detailed history followed by a clinical examination to determine the precise location of the foreign body. In older children, a direct history may be possible, while with younger children information provided by the parents must suffice, although both the children and parents are often unable to recount the incident (1-7).

Foreign bodies can be found in the ear, nose and throat, pharynx, esophagus, larynx and the tracheobronchial system. Most foreign bodies above the larynx can be removed easily in compliant children. Here the child's age and location of the foreign body play a major role. In general, the older the patient, the easier it is to remove the foreign body. If the examination or removal process proves difficult, then an individual evaluation is required to determine whether extraction should be performed under general anesthesia, in order to ensure the patient's safety, min- imize the risk of iatrogenic complications such as eardrum injury, hemorrhaging, aspiration of the foreign body as well as emotional trauma of the child during the procedure $(1,2,4,5,8-18)$.

\section{Objectives}

The primary aim of this study was to analyze the caseload and first aid management over a 5-year time period of children presenting with foreign bodies to the Charite University Berlin, campus Virchow clinic and managed by the attending otorhinolaryngologist from the ENT department.

\section{Methods}

Data was extracted retrospectively from the software systems SAP, MedVision and Opdis for all children aged 0 - 14 years presenting to the emergency department of the 
Charite University Berlin, campus Virchow clinic, and reviewed by the attending otolaryngologist between 2009 and 2013. Specific search for foreign bodies was based on the ICD-10-keys (international statistical classification of diseases and related health problems, version 10), and the following ICD-10-keys were selected as relevant for the analysis:

-T16 = Foreign bodies in the ear, including the ear canal

-T17.1 = Foreign bodies in the nasal cavity, including: nasal foreign bodies not otherwise specified

-T17.2 = Foreign bodies in the throat, nasopharynx, pharynx not otherwise specified

-T18.0 = Foreign bodies in the mouth

Using the above codification, a systematic evaluation based on the following criteria was performed: age, gender, localization of the foreign body and need for anesthesia vs uncomplicated removal on conscious patients. Furthermore, it was noted whether imaging was necessary in order to precisely localize the foreign body prior to removal.

Statistical analysis was performed using SPS in collaboration with the department of biometry and clinical epidemiology, Charite University Berlin. The Chi-square contingency test, the Kruskal-Wallis test and the MannWhitney test were used. $\mathrm{P}<0.05$. were considered statistically significant.

\section{Results}

A total of 517 children (275 boys, 242 girls) with ENTrelated foreign bodies were included in the study (mean age 4.14).

Most foreign bodies were located in the nasal cavity 237 (54\%), followed by ear 161 (37\%), oropharynx 29 (7\%) and nasopharynx 8 (2\%). Considered separately are 9 ingrown piercings of the lobule, 15 cases where the foreign body was removed by another speciality due to the location and 58 cases where a foreign body wasn't found after a detailed ENT examination.

Of the foreign bodies in the nasal cavity, 95\% (226 items) could easily be removed without anesthesia, with only $5 \%$ (11) requiring general anesthesia. Types of foreign body included: toys/beads (80); plastic/metal objects (52); foodstuffs, mainly peanuts (47); stones (6); button cell batteries (6); insects (3); and flower buds (2) (Figure 1). In 30 cases there was no complete documentation detailing the removed foreign body.

Of the 161 foreign bodies removed from the ear, 39 (24\%) required general anesthesia to ensure safe removal (Figure 2). The most common foreign bodies found in the ear were toys (46) and beads (30), followed by a variety of small plastic objects (36), stones (16) and foodstuffs, mainly peanuts
(16). In 11 cases the suspected foreign body was just cerumen. Rare foreign bodies found were button cell batteries (3), insects (2) and in one case a flower blossom. Considered separately and not as a primary foreign body are 9 cases in which ingrown piercings had to be removed from the lobule.

Foreign bodies were removed from the mouth a total of 29 times, none requiring general anesthesia. In one case the presence of a foreign body was excluded upon examination. Most foreign bodies found were fish bones, mostly in the tonsils and base of the tongue (23 cases). Other foreign bodies removed included toothpicks, a bone chip, a piece of a fruit pit or stone, a button, metal wire and plastic wrap.

Foreign bodies in the nasopharynx are rare. Overall, only 8 foreign bodies were removed. These were two cases of button batteries, three cases of fruit stones, one blade of grass, and two styrofoam balls. General anesthesia was required on one occasion to remove a button battery. Additionally, in 10 cases a suspected foreign body was excluded by an endoscopic ENT examination.

General anesthesia for the removal of the foreign body was necessary in approximately $12 \%$ of cases, the majority of which involved the ear (Table 1).

Table 1. General Summary of the Number of Foreign Bodies Based on Their Location and Removal with or without Anesthesia. The Foreign Bodies' Exclusions are Already Deducted. Percentage and Total Number ${ }^{\mathrm{a}}$

\begin{tabular}{lccc}
\hline Localization & Total & Without Anesthesia & With Anesthesia \\
\hline Ear & $161(37)$ & $122(76)$ & $39(24)$ \\
Nasal cavity & $237(54)$ & $226(95)$ & $11(5)$ \\
\hline Nasopharynx & $8(2)$ & $7(88)$ & $1(12)$ \\
\hline Oropharynx & $29(7)$ & $29(100)$ & $0(0)$ \\
\hline
\end{tabular}

${ }^{\mathrm{a}}$ Values are expressed as No. (\%) unless otherwise indicated.

In a total of 14 cases an X-ray of the sinuses was used as an aid to locate the foreign body. In 10 of those cases, the presence of a foreign body was excluded. In 4 cases the suspected foreign body was confirmed. Twice the $\mathrm{x}$-ray showed a coin and twice a button battery in the nasal cavity.

There was no significant difference between the sexes in terms of the localization of the foreign body ( $\mathrm{P}=$ 0.0966). There was a significant difference in age, with a younger age-group where foreign bodies were removed from the nasal cavity and oropharynx, compared to those with foreign bodies in the ear and nasopharynx $(\mathrm{P}=0.001)$ (Figure 3).

After a detailed ENT-examination 15 foreign bodies were documented at other sites of the digestive tract and 


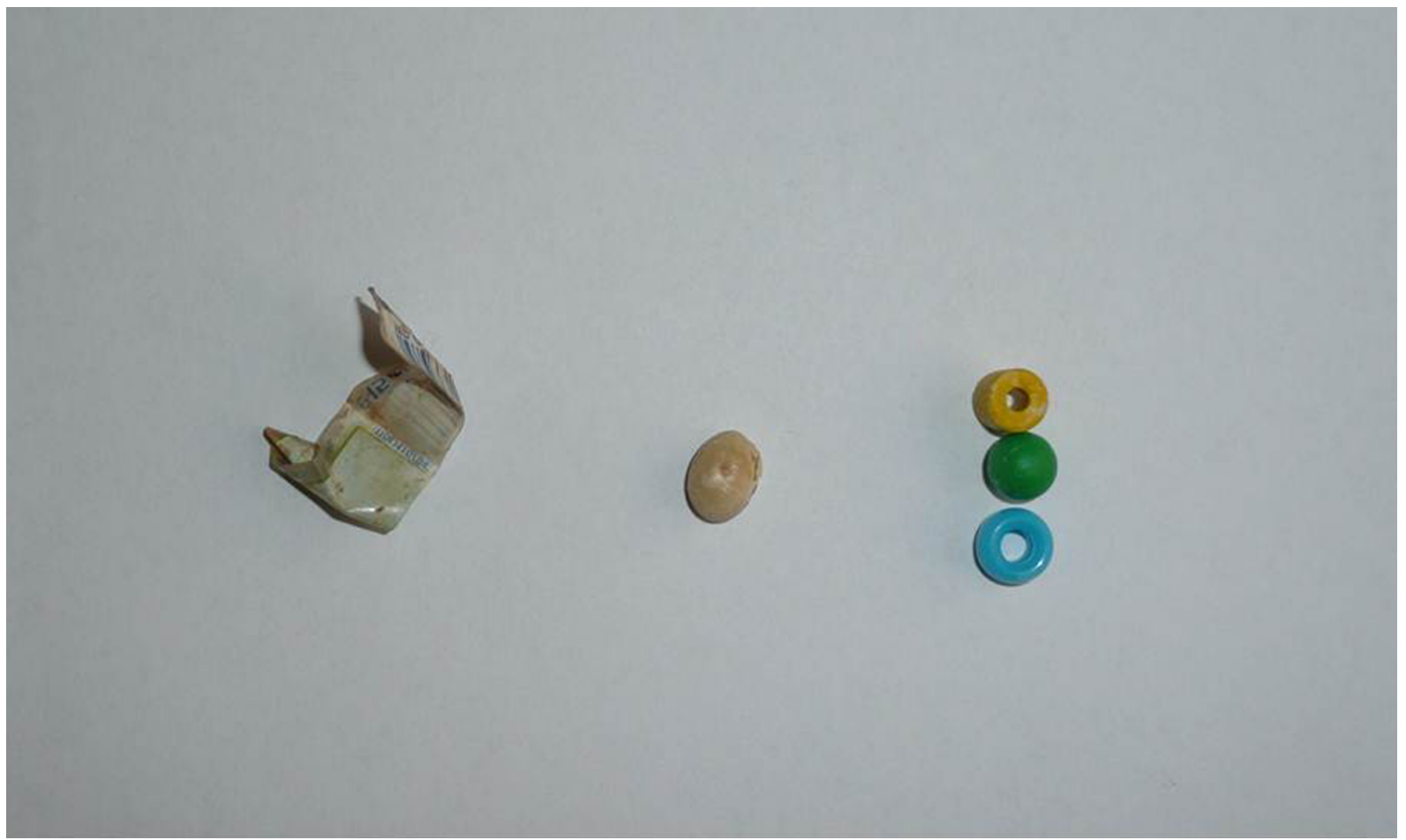

Figure 1. Found Foreign Bodies. Left: an Old Sticker, in the Middle: A Peanut and Right: Three Plastic and Wooden Beads

Figure 2. Shown Here, the Number of Foreign Bodies Ear (Y-axis) is Plotted Against Age (X-Axis)

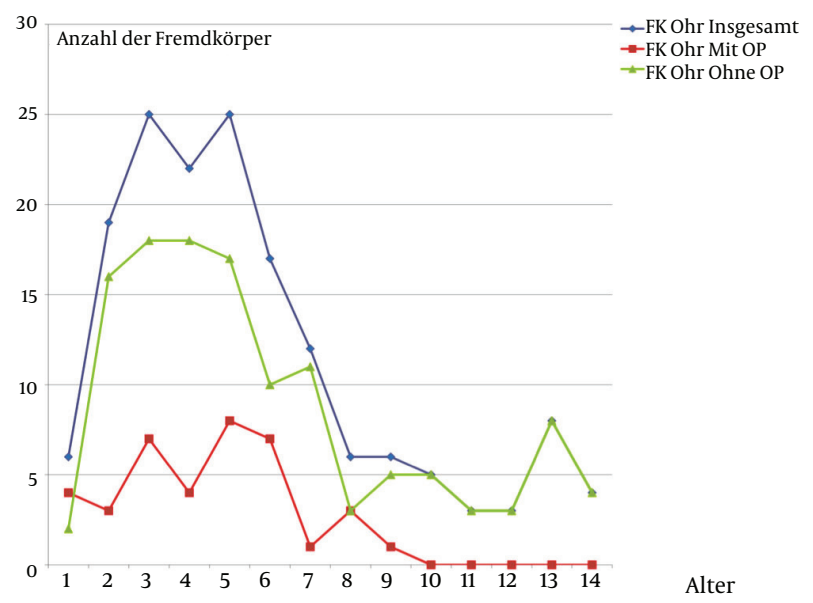

The blue curve represents the number of ear foreign bodies in total, per age group. The green curve represents the ear foreign bodies per age group, which could be removed without anesthesia and the red curve the ear foreign bodies per age group, which were removed under general anesthesia.

the respiratory tract and removed by the appropriate speciality.

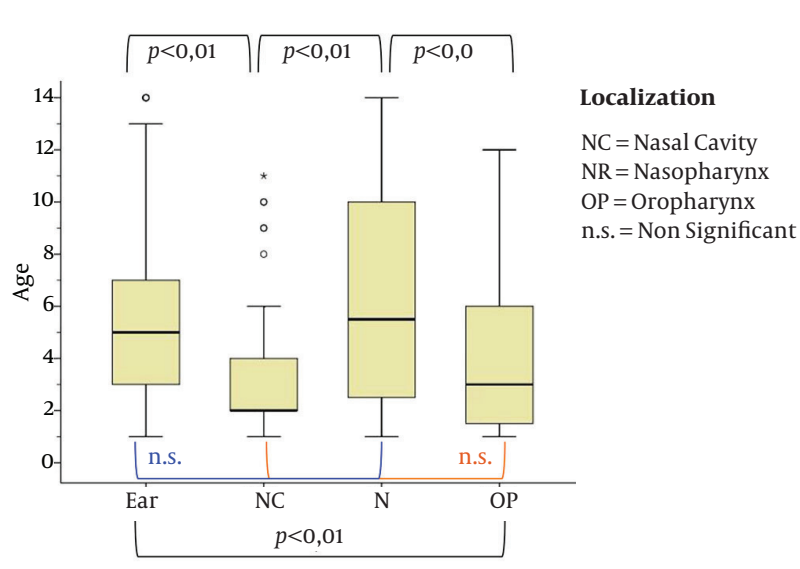

Figure 3. Shown here, the Age Distribution at Time of Accident is Broken Down by the Different Sites.

In total 58 of the 508 children the suspected foreign body could not be confirmed after a thorough history and clinical examination were carried out. These patients were discharged without any further treatment. 


\section{Discussion}

People with foreign bodies in the nose, mouth, larynx and esophagus are part of the regular patient population visiting emergency rooms and first aid stations. Whilst foreign bodies in adults are a well known but rare problem, foreign bodies in children play a greater role in pediatric and ENT medical practice $(1,2,4,7-10,18)$. Primary care for patients with foreign bodies located in the ear, nose or throat is not always directly provided by an ENT doctor, as there are many general accident and emergency departments (A\&E) or hospitals without ENT departments. Children with suspected foreign bodies are therefore often only seen by an otolaryngologist if several unsuccessful attempts at extraction have already been carried out $(1,6,19)$.

The precise history and a physical examination are essential to aid diagnosis and maximize the opportunity to remove the foreign body under safe conditions. Older children can often be directly questioned, but in younger patients the anamnesis has to be taken by the accompanying parents, relatives or caregivers (10).

In our patient population the nasal cavity (237 cases, $54 \%$ ) was most commonly affected, followed by the ear and ear canal (161 cases) the oropharynx (29 cases) and the nasopharynx, with 8 foreign bodies removed. Furthermore, 15 foreign bodies have been documented at other sites of the digestive tract and the respiratory tract. In the literature we find similar information in comparable study populations. Nasal cavity and ear are here regularly the most affected regions for foreign bodies (2, 6, 7, 10-12, 14, 20-22).

The most common foreign body found in our patient population study was a plastic or foam bead. In the literature such objects almost always take the top spot on the list of foreign bodies found in the ENT field in children (6, 10). In general, the extraction of foreign bodies from the nasal cavity is possible without anesthesia; only $5 \%$ of the children studied had a general anesthetic for the removal.

The second most common location for foreign bodies is the ear, including the ear canal. These objects were the most likely to require anesthesia for removal (24\%). In the literature the use of anesthetics for removal of ear foreign bodies is also described, especially when unsuccessful attempts had already been made in other departments $(6,9$, 11, 14, 22, 23).

This may be due to anatomical limitations, the pain sensitivity of the ear canal and tympanic membrane, the noise level, and the risk of injuring nearby anatomical structures during the removal of a foreign body. Therefore a lower threshold for general anesthesia is justified in an uncooperative child in this patient group. If, after removal of the foreign body there is a macerated ear canal, a local treatment with non-ototoxic antibiotic drops, or a combination product consisting of a non-ototoxic antibiotic with cortisone is indicated.

If assessment alerts the suspicion that the foreign body could be aspirated or swallowed, an interdisciplinary collaboration with pediatric gastroenterologists and/or pediatric surgeons is very important. Depending on the type of foreign body, a flexible bronchoscopy or a esophagogastroscopy may be indicated, or in very special cases even a thoracotomy or laparotomy for the recovery of the foreign body may be necessary $(4,8,13,15-17,24)$. We did not include these cases in this study.

In our observation, there was no gender difference with respect to the foreign body localization in line with corresponding literature (10).

There does however, appear to be a correlation between the localization of foreign bodies retrieved and age. Children with nasal cavity and oropharyngeal foreign bodies were significantly younger than children with ear and nasopharyngeal foreign bodies. This can be explained by superior haptics and motor function in older children, as well as longer periods of unattended playtime.

Imaging to locate the foreign body played a rather subordinate role in our patient group. When available, a detailed medical history with clinical examination was sufficient in most cases. Only $3 \%$ of the cases required x-rays to locate the foreign body. But negative findings on X-rays do not exclude foreign bodies, since they can be radiolucent if made from plastic, wood or glass $(1,10)$.

In addition to a non-traumatic removal of the foreign body, attention must be paid to reactions caused by the foreign bodies or to complications arising from it. The button battery, for example, can cause greater collateral damage. Even harmless foreign bodies can cause complications after a very long period of time, for example, in the nose. Thus, it is important to ask about the duration of signs and symptoms such as a strictly unilateral rhinorrhea (3, 23, 25). These diagnostic techniques should be used to locate quickly and safely recover foreign bodies. Interdisciplinary cooperation is very important. The ENT doctor, because of his or her expertise and access to equipment, is in most cases, best suited for the atraumatic removal of foreign bodies from the ear, nose, mouth and the upper aerodigestive tract $(1,7,10,19,21)$.

\subsection{Conclusion for Clinical Practice}

The management of foreign objects in the ear, nose and throat in children should be adapted to the location, the nature of the foreign object and the child's age/compliance in order to ensure a safe and gentle removal. Interdisciplinary collaboration is required in particular to avoid complications. Furthermore, primary care by an ENT specialist if possible, is desirable, since he/she has the neces- 
sary expertise and the appropriate instruments to maximize the opportunity for a gentle, non-traumatic removal of foreign object.

\section{References}

1. Adhikary B, Bora H, Bandyopadhyay SN, Sen I, Basu SK. Foreign body in ENT-general practitioner's duty. J Indian Med Assoc. 2008;106(5):3079. [PubMed: 18839637].

2. Chinski A, Foltran F, Gregori D, Passali D, Bellussi L. Nasal foreign bodies: the experience of the Buenos Aires pediatric otolaryngology clinic. Pediatr Int. 2011;53(1):90-3. doi: 10.1111/j.1442-200X.2010.03176.X. [PubMed: 20500553].

3. Claudet I, Salanne S, Debuisson C, Marechal C, Rekhroukh H, Grouteau E. [Nasal foreign body in infants]. Arch Pediatr. 2009;16(9):1245-51. doi: 10.1016/j.arcped.2009.06.005. [PubMed: 19577906].

4. Chavoshzadeh Z, Golnabi A, Rezaei N, Mehdizadeh M. Laryngeal foreign body aspiration misdiagnosed as asthma: two case reports and a review of the literature. B-ENT. 2011;7(2):137-40. [PubMed: 21838100].

5. Kitcher E, Jangu A, Baidoo K. Emergency ear, nose and throat admissions at the korle-bu teaching hospital. Ghana Med J. 2007;41(1):9-11. [PubMed: 17622332].

6. Mackle T, Conlon B. Foreign bodies of the nose and ears in children. Should these be managed in the accident and emergency setting? Int J Pediatr Otorhinolaryngol. 2006;70(3):425-8. doi: 10.1016/j.ijporl.2005.07.007. [PubMed:16125254].

7. Rourke T, Tassone P, Philpott C, Bath A. ENT cases seen at a local 'walkin centre': a one year review. J Laryngol Otol. 2009;123(3):339-42. doi: 10.1017/S0022215108002508. [PubMed: 18485251].

8. Chinski A, Foltran F, Gregori D, Ballali S, Passali D, Bellussi L. Foreign Bodies in the Oesophagus: The Experience of the Buenos Aires Paediatric ORL Clinic. Int J Pediatr. 2010;2010 doi: 10.1155/2010/490691. [PubMed: 20886022].

9. Chinski A, Foltran F, Gregori D, Passali D, Bellussi L. Foreign bodies in the ears in children: the experience of the Buenos Aires pediatric ORI clinic. Turk J Pediatr. 2011;53(4):425-9. [PubMed: 21980845].

10. Endican S, Garap JP, Dubey SP. Ear, nose and throat foreign bodies in Melanesian children: an analysis of 1037 cases. Int J Pediatr Otorhinolaryngol. $\quad$ 2006;70(9):1539-45. doi: 10.1016/j.ijporl.2006.03.018. [PubMed: 16707167].

11. Gregori D, Morra B, Berchialla P, Salerni L, Scarinzi C, Snidero S, et al. Foreign bodies in the ears causing complications and requiring hospitalization in children 0-14 age: results from the ESFBI study. Auris Nasus Larynx. 2009;36(1):7-14. doi:10.1016/j.anl.2008.01.007.[PubMed: 18513905].

12. Gregori D, Salerni L, Scarinzi C, Morra B, Berchialla P, Snidero S, et al. Foreign bodies in the nose causing complications and requiring hos- pitalization in children 0-14 age: results from the European survey of foreign bodies injuries study. Rhinology. 2008;46(1):28-33. [PubMed: 18444489].

13. Gregori D, Salerni L, Scarinzi C, Morra B, Berchialla P, Snidero S, et al. Foreign bodies in the upper airways causing complications and requiring hospitalization in children aged 0-14 years: results from the ESFBI study. Eur Arch Otorhinolaryngol. 2008;265(8):971-8. doi: 10.1007/s00405-007-0566-8. [PubMed:18210146].

14. Iseh KR, Yahaya M. Ear foreign bodies: observations on the clinical profile in Sokoto, Nigeria. Ann Afr Med. 2008;7(1):18-23. [PubMed: 18702244].

15. Khan MA, Hameed A, Choudhry AJ. Management of foreign bodies in the esophagus. J Coll Physicians Surg Pak. 2004;14(4):218-20. [PubMed: 15228825].

16. Passali D, Lauriello M, Bellussi L, Passali GC, Passali FM, Gregori D. Foreign body inhalation in children: an update. Acta Otorhinolaryngol Ital. 2010;30(1):27-32. [PubMed: 20559470].

17. Boudewyns A, Claes J, Van de Heyning P. Clinical practice: an approach to stridor in infants and children. Eur J Pediatr. 2010;169(2):135-41. doi: 10.1007/s00431-009-1044-7. [PubMed: 19763619].

18. Chinski A, Foltran F, Gregori D, Passali D, Bellussi L. Foreign bodies causing asphyxiation in children: the experience of the Buenos Aires paediatric ORL clinic. J Int Med Res. 2010;38(2):655-60. doi: 10.1177/147323001003800228. [PubMed: 20515579].

19. Coulet O, Thiery G, Gal M, Drouet Y, Liard O, Tomasi M. [Extracting a foreign body from the nasal fossa without an ENT specialist]. Med Trop (Mars). 2008;68(1):83-6. [PubMed:18478779].

20. Schulze SL, Kerschner J, Beste D. Pediatric external auditory canal foreign bodies: a review of 698 cases. Otolaryngol Head Neck Surg. 2002;127(1):73-8. doi: 10.1067/mhn.2002.126724. [PubMed: 12161734].

21. Singh GB, Sidhu TS, Sharma A, Dhawan R, Jha SK, Singh N. Management of aural foreign body: an evaluative study in 738 consecutive cases. Am J Otolaryngol. 2007;28(2):87-90. doi: 10.1016/j.amjoto.2006.06.018. [PubMed:17362812].

22. Thompson SK, Wein RO, Dutcher PO. External auditory canal foreign body removal: management practices and outcomes. Laryngoscope. 2003;113(11):1912-5. [PubMed:14603046].

23. Figueiredo RR, Azevedo AA, Kos AO, Tomita S. Complications of ent foreign bodies: a retrospective study. Braz J Otorhinolaryngol. 2008;74(1):7-15. [PubMed: 18392495].

24. Gregori D, Scarinzi C, Morra B, Salerni L, Berchialla P, Snidero S, et al. Ingested foreign bodies causing complications and requiring hospitalization in European children: results from the ESFBI study. Pediatr Int. 2010;52(1):26-32. doi: 10.1111/j.1442-200X.2009.02862.x. [PubMed: 19419514]

25. Bachmann J, Niewels A, Henschke F, Folz B. [A dangerous nasal foreign body: the button battery]. Laryngorhinootologie. 2009;88(2):116-8. doi: 10.1055/s-2008-1077754. [PubMed: 19034826]. 